\title{
THE EFFECT OF THE CONCENTRATION OF GOLDEN HAMSTER SPERMATOZOA ON THE ACROSOME REACTION AND EGG PENETRATION IN VITRO
}

\author{
PRUDENCE TALBOT, L. E. FRANKLIN AND E. N. FUSSELL
}

Department of Biology, University of Houston, Houston, Texas 77004, U.S.A.

\section{(Received 22nd August 1973)}

Epididymal spermatozoa of the golden hamster can undergo the acrosome reaction and subsequently penetrate eggs in vitro in a variety of heat-pretreated blood sera (Yanagimachi, 1970; Barros \& Garavagno, 1970).

This report describes the effect of varying sperm concentration on the acrosome reaction and sperm penetration of eggs in vitro using heat-pretreated $\left(60^{\circ} \mathrm{C}\right.$ for $\left.1 \mathrm{hr}\right)$ blood sera. The relationship between sperm concentration and occurrence of the acrosome reaction was examined in the blood sera of five mammalian species, including baboon, chimpanzee, hamster, rhesus monkey and rabbit (rabbit anti-hamster sperm-immune serum). Two additional experiments examined the relationship between sperm concentration and capacitation, i.e. the capacity, as classically defined, of spermatozoa to penetrate eggs (Text-fig. 3).

Stock sperm suspensions were collected in normal saline from lacerated cauda epididymidis. The sperm concentration of the stock suspension was determined turbidimetrically from a previously prepared standard concentration curve. The calculated standard error for this procedure was $\pm 2.5 \%$. Aliquots $(0.05 \mathrm{ml})$ of sera placed under paraffin oil were inoculated with $5-\mu 1$ samples of sperm suspensions which had been serially diluted with normal saline. In the egg-penetration experiments, a cumulus clot containing superovulated eggs from one ovary was also present in the incubation aliquot. All incubations were carried out in air at $37^{\circ} \mathrm{C}$ for $4 \mathrm{hr}$.

The data in Text-fig. 1 show that each serum differed in its ability to support the occurrence of the acrosome reaction; however, the percentage of spermatozoa which reacted when the sperm concentration was varied followed the same pattern in all five sera. The highest percentage of acrosome reactions occurred between sperm concentrations of $3 \times 10^{5}$ to $3 \times 10^{6} / 0.05 \mathrm{ml}$. To achieve a better resolution of the optimal sperm concentration for occurrence of acrosome reactions, baboon serum was diluted 1:1 with normal saline and was used experimentally as described previously. The results shown in Text-fig. 2 indicate that the percentage of spermatozoa showing the reaction was highest at $1 \times 10^{6} / 0.05 \mathrm{ml}$. Sperm activity and survival did not diminish during the incubation periods except at concentrations exceeding $4 \times 10^{6} / 0.05 \mathrm{ml}$. It seems especially interesting that spermatozoa in rabbit anti-hamster sperm- 


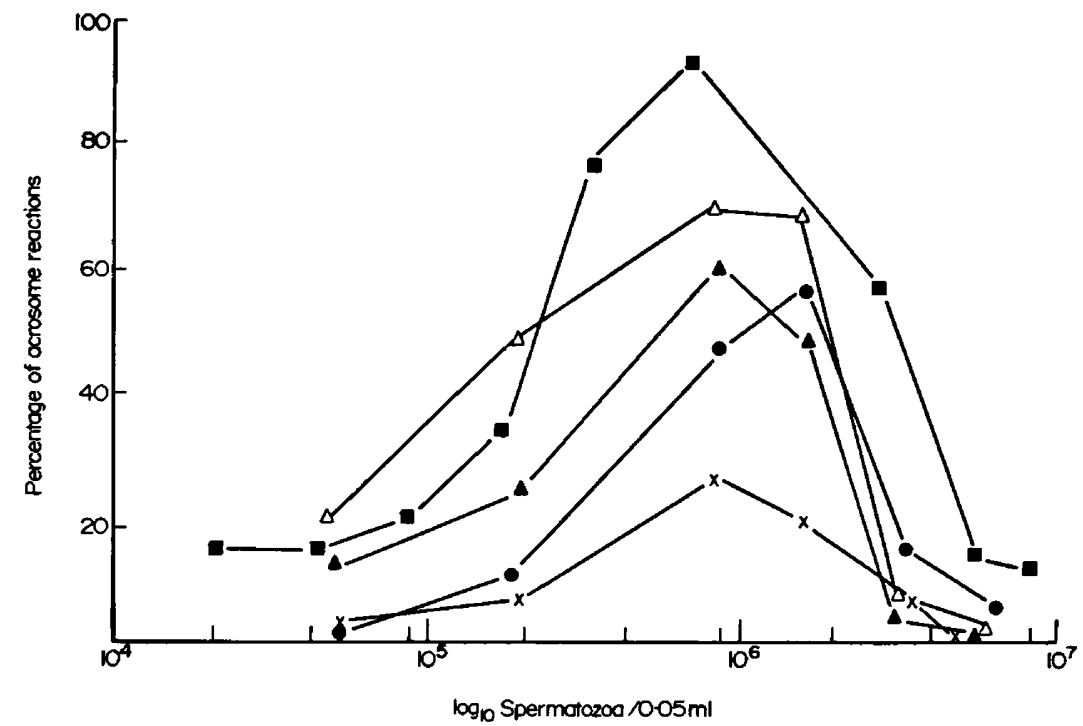

TexT-FIG. 1. Percentage of golden hamster sperm acrosome reactions occurring at various sperm concentrations in five different sera. ( $\square$, baboon serum; $\Delta$, chimpanzee serum; $\Delta$, rabbit anti-hamster sperm serum; $x$, hamster serum; $\bullet$, rhesus monkey serum). Each point is the mean of duplicate or triplicate observations; fifty spermatozoa were counted in each observation.

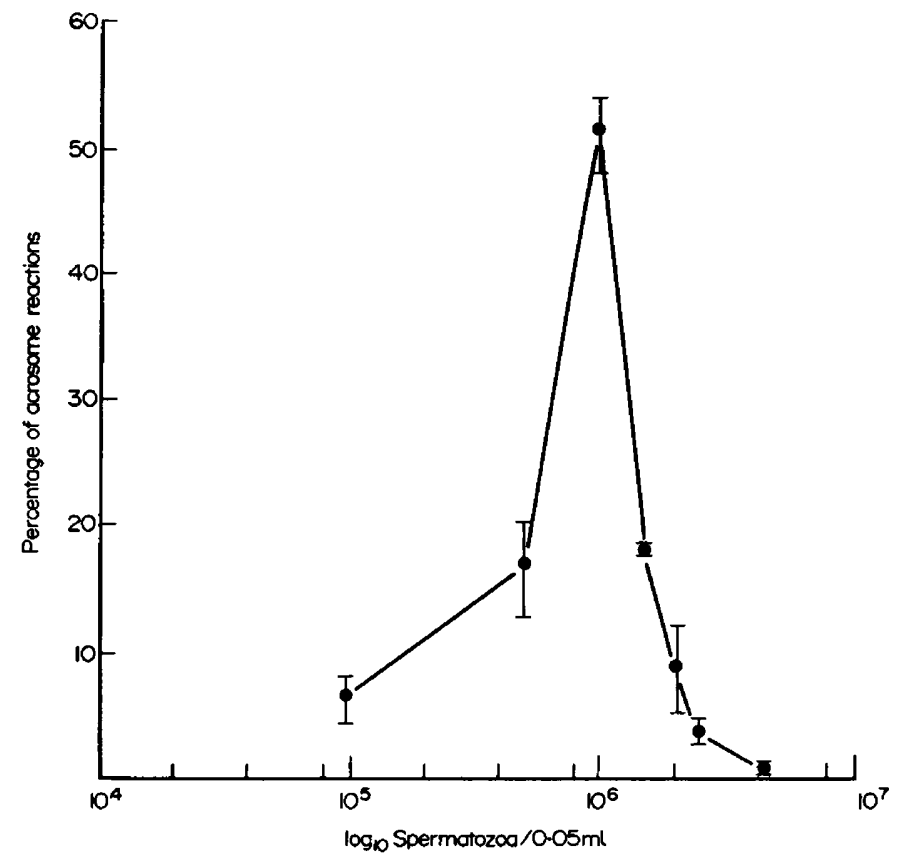

TEXT-FIG. 2. Typical curve showing percentage of golden hamster sperm acrosome reactions as a function of sperm concentration using diluted baboon serum. Each point represents the mean of duplicate trials. 
Table 1. Effect of sperm concentration, sperm number, and incubation volume on the acrosome reaction of golden hamster spermatozoa

\begin{tabular}{|c|c|c|c|c|}
\hline $\begin{array}{l}\text { Actual incubation } \\
\text { sperm numberl } \\
\text { volume of serum }\end{array}$ & $\begin{array}{c}\text { Equivalent sperm } \\
\text { concentration } \\
\text { expressed per } \\
0.05 \mathrm{ml}\end{array}$ & \multicolumn{3}{|c|}{$\begin{array}{l}\text { Percentage acto- } \\
\text { some reactions } \\
\text { (duplicate trials) } \\
A \quad B \quad \text { Mean }\end{array}$} \\
\hline $\begin{array}{l}1 \times 10^{5} / 0.05 \mathrm{ml} \\
1 \times 10^{6} / 0.05 \mathrm{ml} \\
1 \times 10^{6} / 0.2 \mathrm{ml} \\
4 \times 10^{6} / 0.2 \mathrm{ml} \\
1 \times 10^{6} / 0.5 \mathrm{ml} \\
1 \times 10^{7} / 0.5 \mathrm{ml}\end{array}$ & $\begin{array}{r}1 \times 10^{5} \\
1 \times 10^{6} \\
2.5 \times 10^{5} \\
1 \times 10^{6} \\
1 \times 10^{5} \\
1 \times 10^{6}\end{array}$ & $\begin{array}{r}4 \\
36 \\
8 \\
68 \\
4 \\
4 \\
42\end{array}$ & $\begin{array}{r}4 \\
46 \\
6 \\
52 \\
0 \\
60\end{array}$ & $\begin{array}{r}4 \\
41 \\
7 \\
60 \\
2 \\
51\end{array}$ \\
\hline
\end{tabular}

immune serum were influenced by varying the sperm concentration in the same manner as spermatozoa in other sera.

The results of the experiment recorded in Table 1 indicate that the sperm concentration effect holds for different volumes of incubation medium and is a function of sperm concentration, not of sperm number.

The data of Text-fig. 3 show that the relationship between sperm concentration and sperm penetration of eggs is essentially the same as with the acrosome reaction. Eggs in Exp. 1 were collected $18 \mathrm{hr}$ after HCG injection whereas those in Exp. 2 were collected $14 \mathrm{hr}$ after injection. This age difference may account for the difference in amplitude between the egg penetration curves.

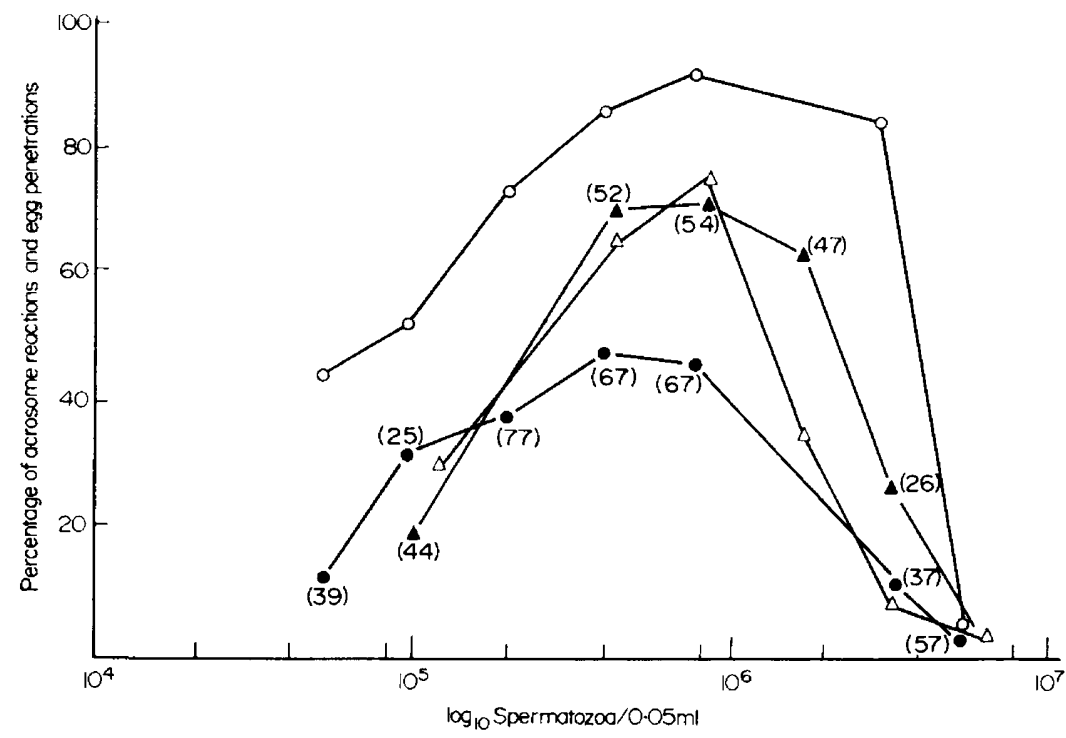

TExT-Fig. 3. Percentage of golden hamster sperm acrosome reactions and penetrated eggs at various sperm concentrations. Exp. 1: $O$, acrosome reactions; $\bullet$, egg penetrations. Exp. 2: $\triangle$, acrosome reactions; $\Delta$, egg penetrations. The number of eggs examined for each point is given in parentheses. 
Results from these experiments demonstrate for the in-vitro system described that there exists an optimum sperm concentration for obtaining a maximum percentage of acrosome reactions and that this optimum is independent of the species source of serum used as the incubation medium. Furthermore, the penetration of eggs varies as a function of the sperm concentration, and the optimal sperm concentration for maximum percentage of egg penetrations and acrosome reactions is the same.

The drop in percentage of acrosome reactions and eggs penetrated at sperm concentrations above $1 \times 10^{6} / 0.05 \mathrm{ml}$ could be due to exhaustion of some metabolite or accumulation of some toxic product, especially at the highest concentrations where survival and activity decreased. The decline in acrosome reactions at concentrations below $1 \times 10^{6} / 0.05 \mathrm{ml}$ was unexpected and was not due to a decrease in sperm viability at the lower concentrations. The decrease in percentage of penetrated eggs below $1 \times 10^{6}$ spermatozoa $/ 0.05 \mathrm{ml}$ was perhaps due to the diminishing probability of an egg and capacitated spermatozoa colliding. Interestingly, the total number of spermatozoa present at the site of fertilization in vivo has been reported to be 17 to 500 (Braden \& Austin, 1954). In vitro, the presence of excessive numbers of spermatozoa showing an acrosome reaction in the vicinity of eggs is not by itself sufficient to ensure high percentages of penetrated eggs.

In summary, this study establishes that for experiments with hamster gametes in vitro, using serum culture media, the acrosome reaction and egg penetration are affected by sperm concentration. This may explain some instances in the literature where egg penetration percentages have been low.

This work was supported by grant HD 07346 from the National Institutes of Health, Department of Health, Education and Welfare. We are grateful to Professor C. R. Austin for reading this manuscript.

\section{REFERENCES}

Barros, C. \& Garavagno, A. (1970) Capacitation of hamster spermatozoa with blood sera. F. Reprod. Fert. 22, 381.

Braden, A. W. H. \& Austin, G. R. (1954) The numbers of sperms about the eggs in mammals and its significance for normal fertilization. Aust. 7. biol. Sci. 7, 543.

YANAGIMACHI, R. (1970) In vitro capacitation of golden hamster spermatozoa by homologous and heterologous blood sera. Biol. Reprod. 3, 147. 